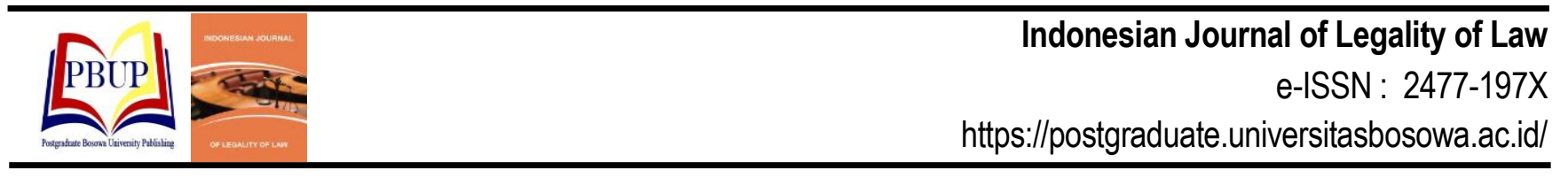

\title{
EFEKTIVITAS FUNGSI PEMBIMBING KEMASYARAKATAN TERHADAP PENGAWASAN KLIEN ANAK KASUS NARKOTIKA DI LEMBAGA PENYELENGGARA KESEJAHTERAAN SOSIAL
}

\author{
The Effectiveness of the Social Advisers' Function on the Supervision of Child Clients with Narcotics \\ Cases in the Social Welfare Organizations
}

\author{
Soeardi ${ }^{1}$, Ruslan Renggong², Baso Madiong ${ }^{2}$ \\ ${ }^{1}$ Magister Ilmu Hukum Program Pascasarjana Universitas Bosowa \\ ${ }^{2}$ Program Studi Ilmu Hukum Program Pascasarjana Universitas Bosowa
}

Email: rismahamzah@gmail.com

Diterima: 25 Juni 2020/Disetujui: 07 Desember 2020

\begin{abstract}
ABSTRAK
Penelitian ini bertujuan mengetahui efektivitas fungsi pembimbing kemasyarakatan terhadap pengawasan klien anak kasus narkotika di Lembaga Penyelenggara Kesejahteraan Sosial (LPKS) serta kendala yang mempengaruhi efektivitas fungsi pengawasan pembimbing kemasyarakatan terhadap klien anak kasus narkotika di LPKS tersebut. Jenis penelitian yang digunakan adalah penelitian hukum empiris. Lokasi penelitian di LPKS yang berbentuk Balai Rehabilitasi Sosial Anak Memerlukan Perlindungan Khusus (BRSAMPK) Toddopuli Makassar dan di Balai Pemasyarakatan (Bapas) Kelas I Makassar. Responden penelitian ini adalah petugas pembimbing kemasyarakatan Bapas Kelas I Makassar yang menangani klien anak. Metode pengumpulan data menggunakan teknik wawancara dan kepustakaan. Berdasarkan hasil penelitian dan analisis data yang dilakukan peneliti, disimpulkan bahwa efektivitas fungsi pembimbing kemasyarakatan terhadap pengawasan klien anak kasus narkotika di BRSAMPK Toddopuli Makassar belum terlaksana secara optimal. Efektivitas fungsi pengawasan pembimbing kemasyarakatan dilakukan dalam 3 (tiga) tahap yakni tahap pelaksanaan pengawasan yakni pengawasan langsung dan pengawasan tidak langsung, tahap pembimbingan yakni pemberian saran, nasihat dan motivasi, serta tahap evaluasi dan pelaporan yang dilaksanakan secara periodik. Adapun kendala pelaksanaan fungsi pengawasan pembimbing kemasyarakatan terhadap klien anak yakni keterbatasan sumber daya manusia (SDM), keterbatasan anggaran, koordinasi antar lembaga kurang optimal, cakupan wilayah kerja Bapas Kelas I Makassar yang sangat luas, serta kurangnya peran orangtua dan keluarga klien anak dalam mendukung upaya rehabilitasi bagi klien anak tersebut.
\end{abstract}

Kata Kunci : Efektivitas, Pengawasan, Pembimbing Kemasyarakatan, Anak, LPKS, Balai Pemasyarakatan

\begin{abstract}
This study aims to determine the effectiveness of the social advisers' function in the supervision of child clients with narcotics cases at the Social Welfare Organizations (LPKS) as well as the constraints that affect the effectiveness of the supervisory function for child clients with narcotics cases in the LPKS. This type of research is empirical law research. The research locations were in the LPKS in the form of the Social Rehabilitation Center for Children Needing Special Protection (BRSAMPK) in Toddopuli Makassar and at the Class I Makassar Correctional Center (Bapas). Respondents of this study were social advisers' for Bapas Class I Makassar who handled child clients. Data collection methods used interviews and literature studies. Based on the results, it was concluded that the effectiveness of the social advisers' function in monitoring child clients with narcotics cases at BRSAMPK Toddopuli Makassar has not been implemented optimally. The effectiveness of the social supervisory function is carried out in 3 (three) stages, namely the implementation stage of supervision, which is direct supervision and indirect supervision, the guidance stage, which is the provision of advice and motivation, and the evaluation and reporting stage which is carried out periodically. As for the obstacles in implementing the social supervisory function of child clients, there are limited human resources (HR), budget constraints, less optimal coordination between institutions, the very wide coverage of the Class I Makassar Bapas work area, as well as the lack of the role of parents and families of child clients in supporting rehabilitation efforts for the child clients.
\end{abstract}

Keywords: Effectiveness, Supervision, Social Advisors, Children, LPKS, Correctional Centre

\section{PENDAhuluan}

Perjuangan bangsa yang menjamin kelangsungan eksistensi bangsa dan negara di masa depan. Sebagai bagian dari generasi muda, anak memiliki peranan yang sangat strategis dan mempunyai ciri serta sifat khusus. Oleh karena itu, diperlukan perhatian dan pembinaan 
secara terus menerus demi menjamin kelangsungan hidup, pertumbuhan dan perkembangan fisik, mental dan sosial, serta perlindungan dari segala kemungkinan yang membahayakan atau merusak masa depan anak (Abintoro, 2016)

Akan tetapi, dalam kehidupan sehari-hari sering ditemui anak yang terlibat dalam permasalahan atau kasus hukum, khususnya hukum pidana. Penyimpangan perilaku melanggar hukum yang dilakukan oleh anak dapat menyebabkan anak harus berhadapan dengan hukum. Hal tersebut dipengaruhi oleh berbagai faktor, antara lain; dampak negatif dari perkembangan pembangunan yang cepat, arus globalisasi di bidang komunikasi dan informasi, kemajuan IPTEK, perubahan gaya hidup telah membawa perubahan sosial yang mendasar dalam kehidupan masyarakat, serta kurangnya anak memperoleh bimbingan dan kasih sayang, pembinaan dalam pengembangan sikap dan perilaku, penyesuaian diri serta pengawasan dari orang tua, wali atau orang tua asuh (Atiek, 2018)

Di Indonesia, kasus anak yang berhadapan dengan hukum $(\mathrm{ABH})$ masih cukup tinggi. Berdasarkan data Direktorat Jenderal Pemasyarakatan (Ditjen PAS) Kementerian Hukum dan HAM RI, jumlah ABH di seluruh Indonesia hingga September 2019 mencapai 2.519 anak (Nusantaranews.co, 2019) Sedangkan data dari Kementerian Sosial RI, sebagaimana dilansir dari Tribunjakarta.com, sebanyak 2.200 kasus ABH terdata hingga bulan Desember 2018. Kemudian pada bulan Juli 2019 jumlahnya mengalami kenaikan sebanyak 3.000 kasus.

Komisi Perlindungan Anak Indonesia (KPAI) mengungkapkan bahwa kasus anak yang berhadapan dengan hukum $(\mathrm{ABH})$ merupakan kasus yang paling sering dilaporkan ke KPAI. Berdasarkan data pengaduan, sejak tahun 2011 hingga Juli 2019 jumlah kasus ABH yang dilaporkan ke KPAI mencapai angka 11.492 kasus, jauh lebih tinggi daripada laporan kasus anak terjerat masalah kesehatan dan Napza yakni 2.820 kasus, pornografi dan cyber crime 3.323 kasus, serta trafficking dan eksploitasi sebanyak 2.156 kasus (Suara.com, 2019)

Keberadaan anak yang demikian di lingkungan masyarakat memang perlu mendapatkan perlindungan, khususnya anak yang berhadapan dengan hukum. Karena pada hakekatnya, anak tidak dapat melindungi dirinya sendiri dari berbagai macam tindakan yang menimbulkan kerugian mental, fisik, dan sosial. Anak harus mendapatkan perlindungan oleh individu, kelompok, organisasi, sosial dan pemerintah (Eva, 2011). Khususnya oleh Pembimbing Kemasyarakatan yang mempunyai peranan penting terhadap kesejahteraan anak dan masa depan anak dari berbagai kesalahan penerapan hukum terhadap anak yang menghadapi masalah dengan hukum, terlebih lagi dalam proses penyelesaian perkara pidana oleh anak (Dinda, 2014)

Berdasarkan data Balai Pemasyarakatan (BAPAS) Kelas I Makassar, jumlah ABH hingga bulan September 2019 yakni sebanyak 366 anak. Sedangkan, jumlah Pembimbing Kemasyarakatan (PK) di BAPAS Kelas I Makassar hanya 56 orang dengan wilayah kerja yang cukup luas meliputi; Makassar, Maros, Pangkep, Barru, Pare-Pare, Pinrang, Gowa, Takalar, Jeneponto, Bantaeng, Bulukumba, hingga Selayar. Selain itu, tugas dan tanggungjawab PK tidak hanya meliputi klien anak saja, melainkan juga pada klien dewasa (Badrudin, 2014). Hal inilah yang menjadi tantangan bagi PK untuk melaksanakan perannya dalam konteks perlindungan anak yang berhadapan dengan hukum secara efektif dan professional (Harliyanti, at.al, 2020).

Seiring diberlakukannya Undang-Undang RI Nomor 11 tahun 2012 tentang Sistem Peradilan Pidana Anak, peran seorang pembimbing kemasyarakatan menjadi semakin penting dalam proses penegakkan hukum di Indonesia. Oleh karena itu, seoarang pembimbing kemasyarakatan dituntut untuk dapat meningkatkan pengetahuan dan keterampilan teknisnya agar dapat menjalankan tugas yang semakin menantang. Pembimbing kemsyarakatan mempunyai tugas khusus dalam proses penegakkan hukum. Pembimbing kemasyarakatan merupakan salah satu bagian dari sistem tata peradilan pidana, seperti halnya Polisi, Jaksa, Hakim, dan Pengacara. Pembimbing kemasyarakatan menurut pasal 1 angka 13 Undang-Undang RI Nomor 11 tahun 2012 tentang Sistem Peradilan Pidana Anak adalah pejabat fungsional penegak hukum yang melaksanakan penelitian kemasyarakatan, pembimbingan, pengawasan dan pendampingan terhadap anak di dalam dan di luar proses peradilan pidana (Juhaya, 2014). Oleh karena itu, jika peran dan fungsi PK tidak terlaksana sebagaimana mestinya, maka akan sangat berpengaruh pada efektivitas penegakkan hukum di Indonesia, khususnya pelaksanaan sistem peradilan pidana anak (UU SPPA).

Perubahan paradigma dalam penanganan $\mathrm{ABH}$ di Indonesia terjadi pasca berlakunya Undang-Undang SPPA tahun 2012. Hal ini ditandai dengan dibangunnya prasarana Lembaga Penyelenggara Kesejahteraan Sosial (LPKS) Anak Berhadapan dengan Hukum (ABH) yang berada dibawah koordinasi Kementerian Sosial (Kemensos) dan diperuntukkan bagi anak-anak yang menjalani pidana kurang dari tujuh tahun. Sedangkan, prasarana bagi anak yang menjalani pidana diatas 7 tahun akan ditempatkan di Lembaga Pembinaan Khusus Anak (LPKA) dibawah koordinasi dari Kementerian Hukum dan HAM (Kemenkumham). Sehingga istilah Lapas Anak tidak lagi digunakan, melainkan LPKS-ABH yang dalam pelaksanaan pembinaannya dapat berbentuk Panti Rehabilitasi Sosial Anak ataupun Balai Rehabilitasi Sosial Anak Memerlukan Perlindungan Khusus (BRSAMPK). Hal ini bertujuan untuk memberikan perlindungan terhadap nasib anak, sehingga anak tidak lagi dimasukkan ke lapas orang dewasa melainkan direhabilitasi di LKPS-ABH (Maidin, 2014)

Peran pembimbing kemasyarakatan dalam melakukan pembinaan, pembimbingan dan pengawasan pada anak yang berada di LPKS juga sangat dibutuhkan. Efektivitas pelaksanaan tugas dan fungsi pembimbing kemasyarakatan akan berdampak langsung pada anak yang berada dalam bimbingannya, khususnya pada tahap post adjudikasi dan ABH ditempatkan di LPKS. Tujuan penelitian ini adalah: (1) untuk mengetahui efektivitas fungsi pembimbing kemasyarakatan terhadap pengawasan klien anak kasus narkotika di Lembaga Penyelenggara Kesejahteraan Sosial (LPKS), (2) untuk mengatahui kendala yang mempengaruhi efektivitas fungsi pembimbing kemasyarakatan dalam melaksanakan pengawasan terhadap klien anak kasus narkotika di Lembaga Penyelenggara Kesejahteraan Sosial (LPKS). 


\section{METODE}

\subsection{Jenis Penelitian}

Jenis penelitian ini adalah jenis penelitian hukum empiris. Penelitian hukum empiris merupakan istilah lain yang digunakan dalam penelitian hukum sosiologis, dan dapat juga disebut dengan penelitian lapangan. Penelitian empiris merupakan penelitian yang bertitik tolak pada data primer (Salim, 2014). Penelitian hukum empiris adalah penelitian hukum yang menggunakan fakta-fakta empiris yang diambil dari prilaku manusia, baik prilaku verbal yang didapat dari wawancara, maupun prilaku nyata yang dilakukan melalui pengamatan langsung. Penelitian empiris juga digunakan untuk mengamati hasil dari prilaku manusia yang berupa peninggalan fisik ataupun arsip.

\subsection{Jenis dan Sumber Data}

Sumber data adalah tempat dimana dapat diketemukannya data-data penelitian. Jenis Data yang digunakan dalam penelitian ini ada dua, yakni; (1) Data Primer, yaitu data yang diperoleh langsung saat penelitian seperti, data dari hasil wawancara dengan anggota Pembimbing Kemasyarakatan yang telah ditentukan serta, pihak-pihak yang terkait dengan penelitian. (2) Data Sekunder, yaitu data yang sudah ada dan tersedia, baik yang diperoleh dari Bapas Kelas I Makassar, BRSAMPK Toddopuli Makassar, maupun data dari lembaga lain yang dinilai perlu dan berkaitan dengan penelitian.

\subsection{Teknik Pengumpulan Data}

Adapun cara untuk mengumpulkan data, peneliti lakukan dengan teknik sebagai berikut; (1) Teknik Wawancara (interview), yaitu melakukan tanya jawab secara langsung dan mendalam dengan responden/narasumber yang telah ditentukan, dalam hal ini menggunakan teknik wawancara mendalam (indeep interview). (2) Teknik Kepustakaan, yaitu suatu teknik penelaahan normatif dari beberapa data-data dan dokumen yang telah ada, peraturan perundang-undangan terkait, serta penelahaan beberapa literatur yang relevan penelitian ini.

\section{HASIL DAN PEMBAHASAN}

\subsection{Efektifitas Fungsi Pengawasan Pembimbing Kemasyarakatan terhadap Klien Anak Kasus Narkotika di BRSAMPK Toddopuli Makassar}

Menurut Riswan yang pada saat penelitian dilakukan sedang menjabat sebagai Kepala Seksi Bimbingan Klien Anak di Balai Pemasyarakatan (Bapas) Kelas I Makassar, fungsi pengawasan PK Bapas sangat penting dalam rangka memantau perkembangan sikap klien anak dan memastikan klien anak tersebut mendapatkan pembinaan dan pembimbingan serta perlindungan terhadap hak-haknya selama proses rehabilitasi.

Efektivitas fungsi pengawasan yang dilaksanakan oleh Pembimbing Kemasyarakatan (PK) terhadap klien anak, khususnya yang berkaitan dengan kasus narkotika dan mendapatkan pembinaan di BRSAMPK Toddopuli Makassar dapat dianalisis dalam 3 tahapan, yakni sebagai berikut:

1) Tahap Pelaksanaan Pengawasan oleh Pembimbing Kemasyarakatan

Klien anak yang telah melalui proses hukum di pengadilan dan ditempatkan di BRSAMPK Toddopuli Makassar akan mendapatkan program pembinaan dan pembimbingan secara khusus oleh pihak BRSAMPK
Toddopuli Makassar. Pada tahapan post adjudikasi ini, klien anak secara penuh menjadi tanggungjawab pihak BRSAMPK Toddopuli Makassar hingga akhir masa pembinaan dijalani oleh klien anak. Peran PK Bapas hanya melaksanakan pengawasan secara rutin terhadap perkembangan klien anak tersebut hingga proses pembinaan selesai dan klien anak dikembalikan kepada keluarga.

Menurut Hasim, selaku petugas PK Bapas yang menangani klien anak, pada tahap pelaksanaan pengawasan oleh PK Bapas terhadap klien anak, khususnya klien anak kasus narkotika di BRSAMPK Toddopuli Makassar, dilakukan dengan 2 cara yakni pengawasan langsung dan pengawasan tidak langsung. Adapun penjelasannya sebagai berikut:

a. Pengawasan Langsung, yakni; petugas PK Bapas secara langsung meninjau dan mengamati perkembangan klien anak di BRSAMPK Toddopuli Makassar. Pengawasan langsung ini ditujukan untuk memastikan sejauhmana perubahan prilaku klien anak.

b. Pengawasan Tidak Langsung, yakni; petugas PK Bapas hanya meminta laporan dan informasi terkait perkembangan pembinaan dan perubahan klien anak yang menjadi tanggungjawabnya secara periodik kepada petugas BRSAMPK Toddopuli Makassar yakni Pekerja Sosial.

Akan tetapi, dari hasil wawancara dengan Hasim petugas PK Bapas Kelas I Makassar dan Asmawati selaku Pekerja Sosial dari BRSAMPK Toddopuli Makassar, diketahui bahwa proses pengawasan langsung oleh PK Bapas belum dapat berjalan optimal karena berbagai kendala teknis dan non teknis yang dihadapi oleh PK Bapas Kelas I Makassar, salah satunya adalah kurangnya koordinasi. Sehingga, pengawasan klien anak dilaksanakan secara tidak langsung oleh PK Bapas yakni dengan mendapatkan informasi maupun laporan dari pihak BRSAMPK Toddopuli Makassar terkait perkembangan klien anak secara periodik.

2) Tahap Pembimbingan oleh Pembimbing

Kemasyarakatan

Menurut Asmawati selaku Pekerja Sosial dari BRSAMPK Toddopuli Makassar, klien anak yang ditempatkan di BRSAMPK Toddopuli Makassar akan mendapatkan program pembinaan dan pembimbingan sebagai bagian dari proses rehabilitasi yang dilaksanakan oleh petugas BRSAMPK Toddopuli Makassar yakni Pekerja Sosial. Selama tahapan pembinaan dan pembimbingan di BRSAMPK Toddopuli Makassar maka klien anak sepenuhnya menjadi tanggungjawab pihak balai.

Menurut Abdul Gani selaku petugas PK Bapas Kelas I Makassar yang menangani klien anak, peran PK Bapas pada tahap ini adalah mengawasi perkembangan klien anak secara rutin agar terus mengikuti program pembinaan dan pembimbingan tersebut secara berkelanjutan. Selain itu, petugas PK Bapas juga mengadakan kunjungan langsung ke BRSAMPK Toddopuli Makassar untuk meninjau klien anak yang menjadi tanggungjawabnya dengan memberikan saran, nasihat, serta semangat kepada klien anak tersebut hingga akhir masa rehabilitasi di BRSAMPK Toddopuli Makassar dan dikembalikan kepada keluarga. Adapun program bimbingan PK Bapas Kelas I Makassar terhadap klien anak di di BRSAMPK Toddopuli Makassar adalah sebagai berikut:

a. Menyadarkan klien anak untuk tidak melakukan kembali pelanggaran hukum/tindak pidana 
b. Menasehati klien untuk selalu dapat menyesuaikan diri dengan lingkungan yang positif/baik

c. Menghubungi dan melakukan kerja sama dengan pihak ketiga/pihak tertentu dalam menyalurkan bakat dan minat klien serta untuk kesejahteraan masa depan dari klien tersebut.

Akan tetapi, berdasarkan hasil wawancara dengan Abdul Gani, diketahui bahwa proses pembimbingan terhadap klien anak kasus narkotika di BRSAMPK Toddopuli Makassar belum dapat dilaksanakan secara maksimal karena padatnya agenda kerja PK Bapas, seperti pembuatan penelitian kemasyarakatan (litmas), pendampingan klien anak, dan agenda rutin lainnya, serta banyaknya kasus anak berkonflik dengan hukum yang harus ditangani oleh petugas PK Bapas di wilayah kerjanya.

3) Tahap Evaluasi \& Pelaporan oleh Pembimbing Kemasyarakatan

Perkembangan klien anak yang mendapatkan pembinaan di BRSAMPK Toddopuli Makassar akan terus diawasi oleh petugas PK Bapas. Evaluasi akan dilaksanakan oleh petugas PK Bapas terkait kemajuan yang dicapai oleh klien anak tersebut setelah mendapatkan pembinaan dan pembimbingan. Selanjutnya, petugas PK Bapas akan membuat laporan perkembangan klien anak tersebut.

Tahapan evaluasi menurut Hasim, disesuaikan dengan kurun waktu pembinaan atau rehabilitasi yang dijalani klien anak di BRSAMPK Toddopuli Makassar. Petugas PK Bapas Kelas 1 Makassar yang menangani klien anak melakukan 2 (dua) kali evaluasi, yakni pertengahan periode rehabilitasi dan akhir masa rehabilitasi. Setelah itu, petugas PK Bapas akan mencatat dan membuat laporan hasil pengawasan dan pembinaan dari klien anak tersebut.

Laporan perkembangan klien anak pada tahap post adjudikasi nantinya akan berguna bagi klien anak dalam proses pengembalian kepada pihak keluarga ataupun Pemerintah setempat. Selain itu, tahapan evaluasi juga berguna bagi petugas PK Bapas untuk memastikan efektivitas pelaksanaan pengawasan dan pembimbingan terhadap klien anak, khususnya klien anak kasus narkotika.

\subsection{Kendala Fungsi Pengawasan Pembimbing \\ Kemasyarakatan Terhadap Klien Anak Kasus Narkotika di BRSAMPK Toddopuli Makassar}

Berdasarkan hasil wawancara dengan Riswan selaku Kepala Seksi Bimbingan Klien Anak di Balai Pemasyarakatan (Bapas) Kelas I Makassar, diperoleh informasi mengenai kendala-kendala yang dialami pembimbing kemasyarakatan dalam menjalankan tugasnya, khususnya dalam pengawasan klien anak kasus narkotika di BRSAMPK Toddopuli Makassar yaitu sebagai berikut:

1) Keterbatasan Sumber Daya Manusia (SDM)

Keterbatasan sumber daya manusia (SDM), baik secara kuantitas maupun kualitas, dari Pembimbing Kemasyarakatan merupakan salah satu kendala dalam pelaksanaan fungsi pengawasan dan pembimbingan oleh Pembimbing Kemasyarakatan terhadap klien anak.

Berdasarkan data jumlah pegawai Balai Pemasyarakatan Kelas I Makassar pada bulan Desember tahun 2019, jumlah pegawai Bapas secara keseluruhan sebanyak 83 orang. Sedangkan, jumlah Pembimbing Kemasyarakatan (PK) yakni sebanyak 56 orang, termasuk Pos Bapas Pinrang 1 orang, Pare-Pare 1 orang, dan Bulukumba 2 orang. Jumlah PK Bapas tersebut dinilai sangat sedikit jika dibandingkan dengan jumlah klien anak yang cukup banyak dan mengalami kenaikkan tiap tahunnya. Untuk mendapatkan gambaran terkait rasio jumlah pegawai Bapas Kelas I Makassar dengan jumlah kasus Anak dapat dilihat pada Table 1. berikut:

Tabel 1.

Rasio Jumlah Pegawai dan Petugas PK dengan Jumlah Kasus ABH Tahun 2018 - 2019 di Bapas Kelas I Makassar

\begin{tabular}{ccccc} 
No & Tahun & $\begin{array}{c}\text { Jumlah } \\
\text { Pegawai }\end{array}$ & $\begin{array}{c}\text { Jumlah } \\
\text { PK }\end{array}$ & $\begin{array}{c}\text { Jumlah Kasus } \\
\text { ABH }\end{array}$ \\
\hline 1. & 2018 & 83 & 56 & 598 \\
\hline 2. & 2019 & 83 & 56 & 614 \\
\hline Sumber: & Hasil Olah Data Primer 2019 & &
\end{tabular}

Sumber: Hasil Olah Data Primer 2019

Tabel 1, dapat dilihat rasio yang cukup signifikan antara jumlah pegawai dan jumlah petugas PK Bapas Kelas I Makassar dengan jumlah kasus Anak yang Berhadapan dengan Hukum (ABH) yang ditangani oleh Bapas Kelas I Makassar sepanjang tahun 2018 dan 2019. Sedangkan, jumlah petugas PK Bapas tidak mengalami penambahan. Untuk mendapatkan gambaran terkait jumlah klien anak kasus narkotika pada tahun 2018 dan 2019 yang ditangani oleh Bapas Kelas I Makassar, perhatikan Tabel 2 berikut:

Tabel 2

Jumlah Klien Anak Kasus Narkotika Bapas Kelas I Makassar Tahun $2018 \& 2019$

\begin{tabular}{cccc}
\hline No & Tahun & $\begin{array}{c}\text { Jumlah Klien Anak Kasus } \\
\text { Narkotika }\end{array}$ & Keterangan \\
\hline 1. & 2018 & 83 & 56 \\
\hline 2. & 2019 & 83 & 56 \\
\hline
\end{tabular}

Sumber: Hasil Olah Data Primer 2019

Tabel 2, diketahui jumlah klien anak kasus narkotika yang ditangani Bapas Kelas I Makassar pada tahun 2018 sebanyak 87 klien anak dan mengalami peningkatan pada tahun 2019 yakni sebanyak 111 klien anak. Jumlah klien anak kasus narkotika tersebut masih lebih banyak daripada jumlah petugas PK Bapas Kelas I Makassar.

Berdasarkan data sekunder yang diperoleh, bahwa dalam satu bulan rata-rata puluhan kasus baru terdaftar di Bapas Kelas I Makassar dan penanganannya tidak dapat dilakukan dalam waktu singkat. Seringkali kasus pada satu bulan belum terselesaikan sudah memasuki bulan baru dengan kasus baru yang harus ditangani sehingga untuk seorang Pembimbing Kemasyarakatan rata-rata menagani tiga atau lebih kasus dalam waktu yang bersamaan.

Kinerja petugas maupun pegawai dari Balai Pemasyarakatan menjadi juga menjadi kurang maksimal dengan adanya rutinitas dalam melaksanakan tugas sehariharinya di kantor yang bersifat monoton dan tidak berkembang. Sedangkan perkara anak yang berhadapan dengan hukum yang ditangani oleh Bapas Kelas I Makassar cukup banyak. Selain itu, program pendidikan dan pelatihan belum secara rutin dilakukan dalam hal meningkatkan kualitas SDM pembimbing kemasyarakatan di Bapas Kelas I Makassar yang berakibat pada perkembangan kinerja dan profesionalitas pegawai Bapas Kelas 1 Makassar.

2) Keterbatasan Anggaran

Berdasarkan hasil wawancara dengan Riswan, selaku Kepala Seksi Bimbingan Klien Anak, diperoleh informasi bahwa kesenjangan anggaran antara Balai Pemasyarakatan dengan aparat penegak hukum yang lain sangat jauh, baik alokasi anggaran operasional, administrasi, maupun kesejahteraan pegawai.

Khusus untuk anggaran operasional Pembimbing Kemasyarakatan dalam melakukan penelitian 
kemasyarakatan, pengawasan, pendampingan dan pembimbingan terhadap klien anak masih sangat terbatas. Sehingga, petugas PK Bapas Kelas I Makassar seringkali menggunakan dana pribadi untuk menunjang kinerjanya di lapangan.

3) Koordinasi yang Belum Optimal dengan BRSAMPK Toddopuli Makassar

Berdasarkan hasil wawancara dengan Hasim selaku petugas PK Bapas Kelas I Makassar yang menangani klien anak yang mendapatkan pembinaan di BRSAMPK Toddopuli Makassar, diketahui bahwa koordinasi antar lembaga Bapas Kelas I Makassar dan BRSAMPK Toddopuli Makassar masih belum optimal. Misalnya, belum adanya sistem koordinasi terkait data dan perkembangan klien anak antar lembaga. Hal ini menyulitkan petugas PK dalam mengawasi perkembangan klien anak, pemberian pembimbingan, serta evaluasi dan pelaporan terhadap klien anak tersebut. Sehingga, pelaksanaan fungsi pengawasan Pembimbing Kemasyarakatan terhadap klien anak, khususnya klien anak yang terkait kasus narkotika yang dibina di BRSAMPK Toddopuli Makassar menjadi kurang efektiv.

4) Luasnya Wilayah Kerja

Berdasarkan hasil wawancara dengan Abdul Gani petugas PK Bapas Kelas I Makassar yang menangani klien anak, diketahui bahwa salah satu kendala yang mempengaruhi kinerja petugas PK adalah luasnya cakupan wilayah kerja Bapas Kelas I Makassar. Seperti yang telah dipaparkan sebelumnya, cakupan wilayah kerja Bapas Kelas I Makassar meliputi; Makassar, Maros, Pangkep, Barru, Pare-Pare, Pinrang, Gowa, Takalar, Jeneponto, Bantaeng, Bulukumba, hingga Selayar. Hal ini jelas sangat tidak proporsional jika dibandingkan dengan jumlah PK Bapas Kelas I Makassar yang hanya berjumlah 56 orang dan hampir sebagian besar petugas PK berdomisili di Kota Makassar karena kantor PK Bapas berada di Kota Makassar.

Kendala terkait luasnya wilayah kerja Bapas Kelas I Makassar juga mempengaruhi efektivitas fungsi pengawasan PK terhadap klien anak kasus narkotika yang dibina di BRSAMPK Toddopuli Makassar. Selain harus melakukan penelitian kemasyarakatan (litmas) terhadap klien anak secara langsung, PK juga harus melakukan pendampingan, pembimbingan dan pengawasan terhadap klien anak pada semua tahapan, baik pra adjudikasi, adjudikasi, dan post adjudikasi secara profesional.

5) Kurangnya Peran Keluarga Klien Anak

Berdasarkan hasil wawancara dengan Hasim selaku petugas PK Bapas Kelas I Makassar yang melaksanakan fungsi pengawasan terhadap klien anak kasus narkotika yang dibina di BRSAMPK Toddopuli Makassar, diketahui bahwa peran keluarga klien anak yang dibina di BRSAMPK Toddopuli Makassar sangat kurang. Kunjungan orang tua dan keluarga lainnya dari klien anak di BRSAMPK Toddopuli Makassar untuk turut serta mengawasi perkembangan pembinaan dan pembimbingan anaknya sangat minim.

Kurangnya perhatian dari keluarga klien anak tersebut untuk turut serta terlibat aktif dalam upaya rehabilitasi klien anak, khususnya yang berkaitan dengan kasus narkotika disebabkan minimnya pemahaman dan kesadaran akan tanggungjawab keluarga serta kesibukan mencari nafkah. Kunjungan dari pihak keluarga hanya sesekali dan hanya untuk melihat keadaan klien anak tersebut.

\section{KESIMPULAN DAN SARAN}

Hasil penelitian dan pembahasan dapat disimpulkan bahwa pembimbing Kemasyarakatan (PK) Bapas Kelas I Makassar dalam melaksanakan fungsi pengawasan terhadap klien anak kasus narkotika di BRSAMPK Toddopuli Makassar menggunakan 3 (tiga) tahapan yakni; tahapan pelaksanaan pengawasan yang dilakukan secara langsung dan tidak langsung, tahapan pembimbingan berupa pemberian saran, nasihat, pelajaran agama dan motivasi, serta tahapan evaluasi dan pelaporan yang dilakukan secara periodik. Fungsi pengawasan Pembimbing Kemasyarakatan (PK) Bapas Kelas I Makassar terhadap klien anak kasus narkotika di BRSAMPK Toddopuli Makassar masih belum optimal. Hal ini disebabkan oleh 5 (lima) kendala yakni; Keterbatasan Sumber Daya Manusia (SDM) Bapas Kelas I Makassar, Keterbatasan Anggaran Bapas Kelas I Makassar dan anggaran operasional, kurang optimalnya koordinasi antar lembaga, yakni Bapas Kelas I Makassar dan BRSAMPK Toddopuli Makassar, luasnya wilayah kerja Bapas Kelas I Makassar, dan yang terakhir kurangnya peran orang tua dan keluarga klien anak dalam mendukung upaya rehabilitasi dan pembimbingan, baik yang dilakukan oleh petugas PK Bapas maupun oleh pegawai dan BRSAMPK Toddopuli Makassar.

\section{DAFTAR PUSTAKA}

Abintoro Prakoso, 2016. Pembaruan Sistem Peradilan Pidana Anak. Yogyakarta: Aswaja Pressindo.

Atiek Meikhurniawati, 2018. Dasar-Dasar Pengawasan. Jakarta: Diklat Bapas.

Badrudin. 2014. Dasar-Dasar Manajemen. Alfabeta, Bandung.

Dinda Maulida, 2017. Peran Lembaga Kesejahteraan Sosial (LPKS) Dinas Sosial Aceh dalam Membina Anak yang Berhadapan dengan Hukum, Skripsi. Banda Aceh: Fakultas Dakwah dan Komunikasi Universitas Islam Negeri Ar-Raniry.

Ditjen Pas. Anak berhadapan hukum. https://nusantaranews.co/Anak-berhadapan-hukum. Diakses pada 8 September 2019

Eva Achjani Zulfa dan Indriyanto Seno Adji, 2011. Pergeseran Paradigma Pemidanaan. Bandung: Lubuk Agung.

Gultom, Maidin. 2014. Perlindungan Hukum Terhadap Anak dan Perempuan. Bandung: PT Refika Aditama.

Harliyanti, H., Renggong, R., \& Haris, A. H. (2021). Efektivitas Peran Pembimbing Kemasyarakatan Dalam Penerapan Restorative Justice Terhadap Anak Pelaku Tindak Pidana Pada Balai Pemasyarakatan Kelas I Makassar. Indonesian Journal of Legality of Law, 2(2), 88-93. https://doi.org/10.35965/ijlf.v2i2.420

International Society for the Systems Science, Ludwig von Bertalanffy (1901-1972), dari www.isss.org/lumLVB.htm, diakses pada tanggal 2 Agustus 2019

Juhaya S Praja, 2014. Teori Hukum Dan Aplikasinya. Bandung: CV. Pustaka Setia.

Kementerian sosial. Jumlah Anak Berhadapan Hukum. https://tribunjakarta.com/jumlah-Anak-berhadapanHukum. Diakses pada 12 Juli 2019

Salim. Syahrum. 2012. Metodologi Penelitian Kuantitatif. Bandung : Cipta Pustaka. 